\title{
NIST Multifunction Calibration System
}

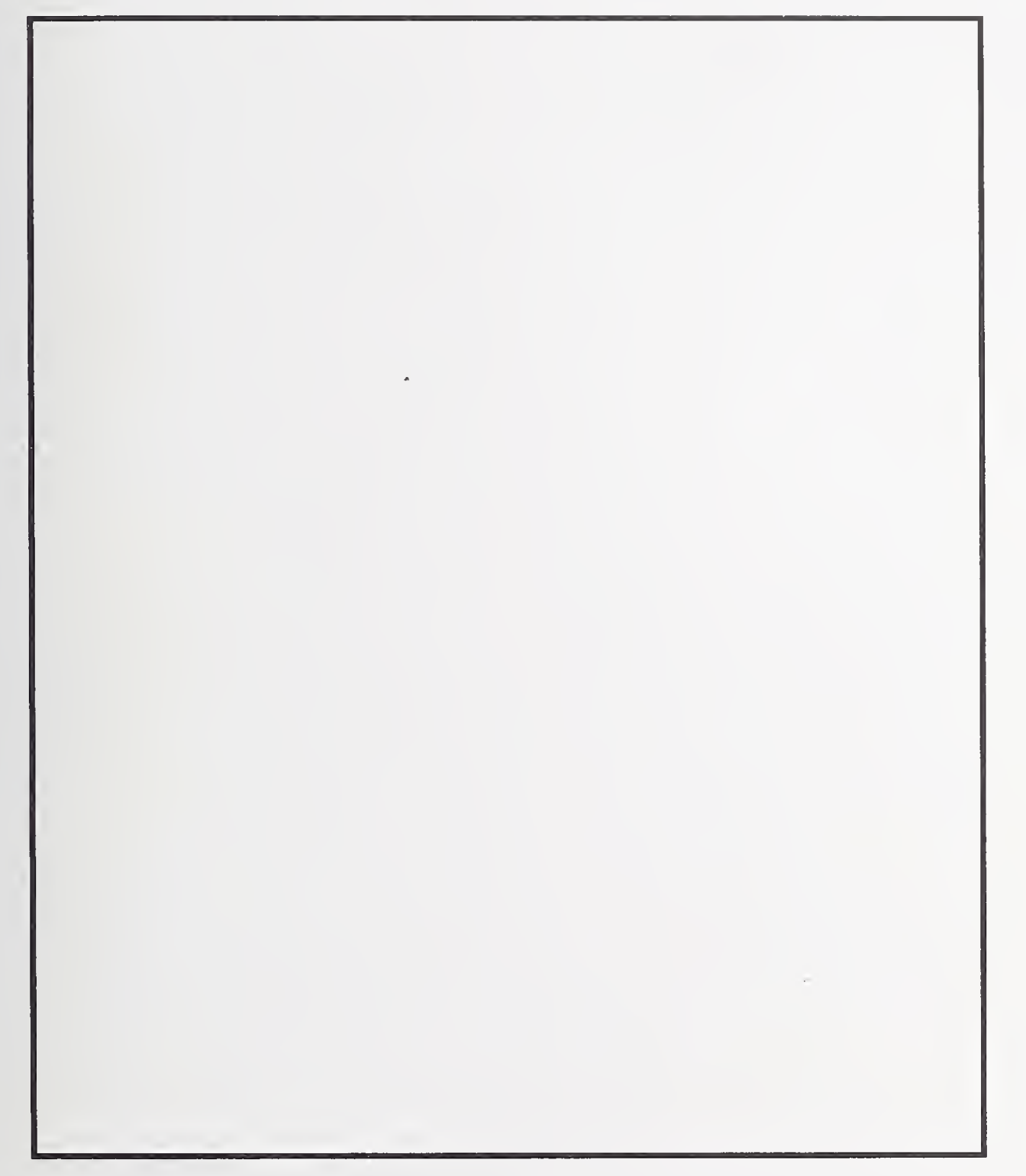

Nile Oldham and Mark Parker

NIST

Special

Publication

250-46

ac

100

457

$0.250-46$ 
he National Institute of Standards and Technology was established in 1988 by Congress to "assist industry in

the development of technology ... needed to improve product quality, to modernize manufacturing processes, to ensure product reliability ... and to facilitate rapid commercialization . . . of products based on new scientific discoveries."

NIST, originally founded as the National Bureau of Standards in 1901, works to strengthen U.S. industry's competitiveness; advance science and engineering; and improve public health, safety, and the environment. One of the agency's basic functions is to develop, maintain, and retain custody of the national standards of measurement, and provide the means and methods for comparing standards used in science, engineering, manufacturing, commerce, industry, and education with the standards adopted or recognized by the Federal Government.

As an agency of the U.S. Commerce Department's Technology Administration, NIST conducts basic and applied research in the physical sciences and engineering, and develops measurement techniques, test methods, standards, and related services. The Institute does generic and precompetitive work on new and advanced technologies. NIST's research facilities are located at Gaithersburg, MD 20899, and at Boulder, CO 80303. Major technical operating units and their principal activities are listed below. For more information contact the Publications and Program Inquiries Desk, 301-975-3058.

Office of the Director

- National Quality Program

- International and Academic Affairs

\section{Technology Services}

- Standards Services

- Technology Partnerships

- Measurement Services

- Technology Innovation

- Information Services

\section{Advanced Technology Program}

- Economic Assessment

- Information Technology and Applications

- Chemical and Biomedical Technology

- Materials and Manufacturing Technology

- Electronics and Photonics Technology

\section{Manufacturing Extension Partnership} Program

- Regional Programs

- National Programs

- Program Development

\section{Electronics and Electrical Engineering} Laboratory

- Microelectronics

- Law Enforcement Standards

- Electricity

- Semiconductor Electronics

- Electromagnetic Fields ${ }^{1}$

- Electromagnetic Technology ${ }^{1}$

- Optoelectronics ${ }^{1}$

\section{Chemical Science and Technology Laboratory \\ - Biotechnology \\ - Physical and Chemical Properties ${ }^{2}$ \\ - Analytical Chemistry \\ - Process Measurements \\ - Surface and Microanalysis Science}

\section{Physics Laboratory}

- Electron and Optical Physics

- Atomic Physics

- Optical Technology

- Ionizing Radiation

- Time and Frequency'

- Quantum Physics'

\section{Materials Science and Engineering} Laboratory

- Intelligent Processing of Materials

- Ceramics

- Materials Reliability ${ }^{1}$

- Polymers

- Metallurgy

- NIST Center for Neutron Research

\section{Manufacturing Engineering}

\section{Laboratory}

- Precision Engineering

- Automated Production Technology

- Intelligent Systems

- Fabrication Technology

- Manufacturing Systems Integration

\section{Building and Fire Research} Laboratory

- Structures

- Building Materials

- Building Environment

- Fire Safety Engineering

- Fire Science

Information Technology Laboratory

- Mathematical and Computational Sciences ${ }^{2}$

- Advanced Network Technologies

- Computer Security

- Information Access and User Interfaces

- High Performance Systems and Services

- Distributed Computing and Information Services

- Software Diagnostics and Conformance Testing

\footnotetext{
'At Boulder, CO 80303.

${ }^{2}$ Some elements at Boulder, $\mathrm{CO}$.
} 


\section{NIST MEASUREMENT SERVICES: NIST Multifunction Calibration System}

Nile Oldham and Mark Parker

Electronic Instrumentation and Metrology Group

Electricity Division

Electronics and Electrical Engineering Laboratory

National Institute of Standards and Technology

Gaithersburg, MD 20899-0001

February 1998

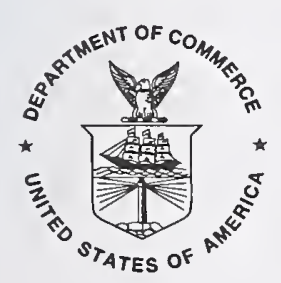

U.S. Department of Commerce

William M. Daley, Secretary

Technology Administration

Gary R. Bachula, Acting Under Secretary for Technology

National Institute of Standards and Technology

Raymond G. Kammer, Director 
National Institute of Standards and Technology Special Publication 250-46 Natl. Inst. Stand. Technol. Spec. Publ. 250-46, 28 pages (Feb. 1998) CODEN: NSPUE2 


\section{TABLE OF CONTENTS}

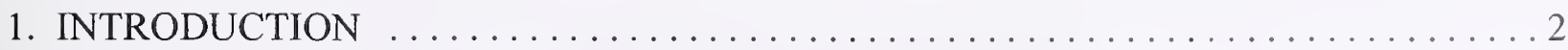

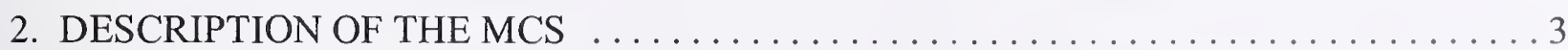

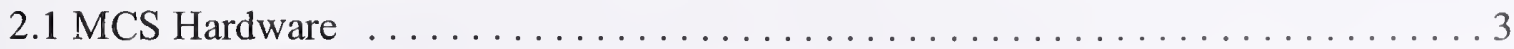

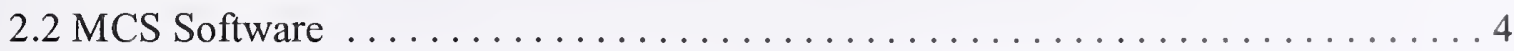

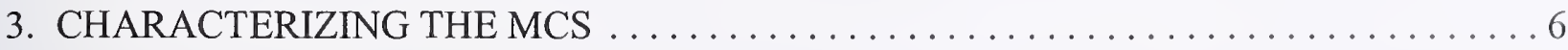

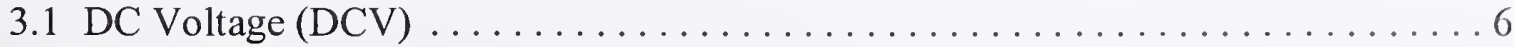

3.2 DC Current (DCI) . . . . . . . . . . . . . . . . . . . . . . . 8

3.3 DC Resistance (DCR) . . . . . . . . . . . . . . . . . . . . . . 10

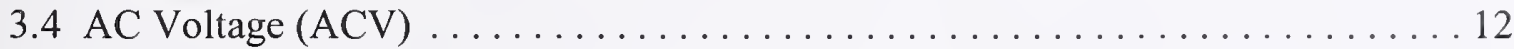

3.4.1 Voltages from $1 \mathrm{mV}$ to $1 \mathrm{kV}$ from $10 \mathrm{~Hz}$ to $1 \mathrm{MHz} \ldots \ldots \ldots \ldots 12$

3.4.2 Voltages from $1 \mathrm{mV}$ to $250 \mathrm{mV}$ from $10 \mathrm{~Hz}$ to $1 \mathrm{MHz} \ldots \ldots \ldots \ldots 14$

3.4.3 Voltage from $250 \mathrm{mV}$ to $7 \mathrm{~V}$ from $10 \mathrm{~Hz}$ to $30 \mathrm{MHz} \ldots \ldots \ldots \ldots$

3.4.4 Voltages from $1 \mathrm{mV}$ to $1 \mathrm{kV}$ from $0.01 \mathrm{~Hz}$ to $1 \mathrm{kHz} \ldots \ldots \ldots \ldots$

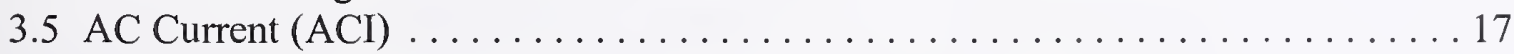

3.5.1 Currents from $2 \mathrm{~mA}$ to $10 \mathrm{~A}$ from $10 \mathrm{~Hz}$ to $100 \mathrm{kHz} \ldots \ldots \ldots \ldots$

3.5.2 Currents from $2 \mathrm{~mA}$ to $10 \mathrm{~A}$ from $0.01 \mathrm{~Hz}$ to $1 \mathrm{kHz} \ldots \ldots \ldots 20$

4. CALIBRATIONS AND TESTS USING THE MCS $\ldots \ldots \ldots \ldots \ldots \ldots \ldots \ldots \ldots \ldots \ldots \ldots \ldots$

4.1 Calibration of DMMs Using the MCS Calibrator . . . . . . . . . . . . 21

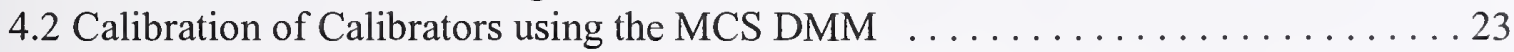

4.3 High Accuracy Special Test of DMMs and Calibrators ................ . 24

4.4 Special Test of Low Voltage Thermal Voltage Converters . . . . . . . . . . . . . . . 24

4.5 Special Test of Micropotentiometers . . . . . . . . . . . . . . . 24

5. QUALITY CONTROL AND UNCERTAINTIES $\ldots \ldots \ldots \ldots \ldots \ldots \ldots \ldots \ldots \ldots \ldots \ldots \ldots \ldots$

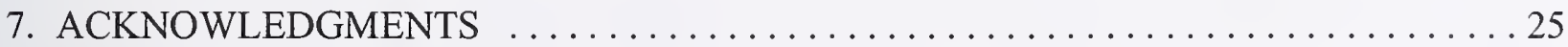

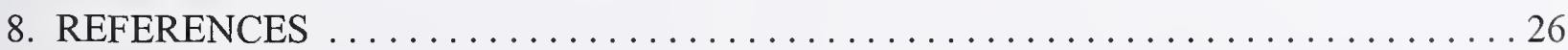




\author{
Nile Oldham and Mark Parker \\ Electronic Instrumentation and Metrology Group \\ Electricity Division \\ National Institute of Standards and Technology \\ Gaithersburg, MD 20899
}

\begin{abstract}
The NIST automated Multifunction Calibration System (MCS) for voltage, current, and resistance is described. Developed primarily to calibrate digital multimeters and calibrators, the system can also be used to test thermal converters, and micropotentiometers. Methods for characterizing the MCS over a wide range of amplitudes at frequencies from dc to $30 \mathrm{MHz}$ are described.
\end{abstract}

\title{
1. INTRODUCTION
}

Digital multimeters (DMMs) from a number of manufacturers claim uncertainties and stabilities that approach those of the laboratory standards used to support them. This is possible because these DMMs are essentially miniature standards labs with built-in zener references, stable resistors, and ac-dc transfer standards, all controlled by a central processor that applies corrections and performs data analysis. In addition to being easier to use than most standards, DMMs are also quite rugged, able to withstand the mechanical and thermal shocks of transportation from one laboratory to another with little degradation in performance. These properties make them ideal transport standards to provide traceability for the five quantities that most DMMs measure (dc voltage, current, and resistance, and ac voltage and current).

The National Institute of Standards and Technology (NIST) offers calibration services ${ }^{1}$ for dc voltage, dc resistance, and the ac-dc difference of thermal converters [1-4]. With these three services, standards laboratories can provide direct NIST traceability for the functions measured by most DMMs. Based on customer demand, special tests ${ }^{2}$ for DMMs (all functions) were offered beginning in 1990 [2-4]. This technical note describes the NIST Multifunction Calibration System (MCS) that is used to provide special test services for DMMs, multifunction calibrators (the programmable sources designed to calibrate DMMs), and special tests for low voltage thermal converters, and micropotentiometers. The MCS is periodically calibrated using reference electrical standards available at NIST. Results of these system calibrations and of frequently performed self-tests are analyzed statistically to maintain quality control of the MCS.

\footnotetext{
${ }^{1}$ NIST calibration services are well documented and analyzed measurements offered at a fixed cost.

${ }^{2}$ NIST special tests are generally undocumented measurements that are charged "at cost."
} 


\section{DESCRIPTION OF THE MCS}

\subsection{MCS Hardware ${ }^{3}$}

A block diagram of the MCS instrumentation is shown in Fig. 1. The basic system is quite simple, consisting of a controller, a characterized calibrator (to test DMMs), and two characterized DMMs (to calibrate calibrators and serve as check standards for the system calibrator).

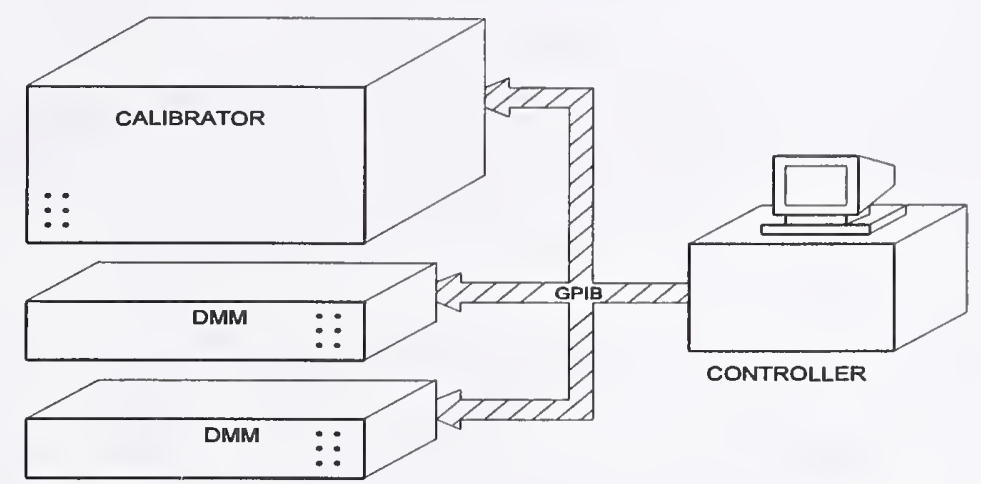

Fig. 1. Simplified diagram of the MCS.

The NIST test facility consists of two such systems which utilize the instruments shown in Table 1:

Table 1

MCS Instrumentation

\begin{tabular}{||c|c||}
\hline System 1 & System 2 \\
\hline Fluke 5720A Multifunction Calibrator & Wavetek 4808 Multifunction Calibrator \\
\hline Hewlett Packard 3458A Digital Multimeter & Hewlett Packard 3458A Digital Multimeter \\
\hline Wavetek 4950 Digital Multimeter & Wavetek 4950 Digital Multimeter \\
\hline PC Controller with GPIB Card & PC Controller with GPIB Card \\
\hline Keithley 7001 Switch System & Keithley 7001 Switch System \\
\hline
\end{tabular}

${ }^{3}$ Commercial instruments and software are identified in this report to describe the measurement system. Such identification does not imply recommendation or endorsement by NIST, nor does it imply that the instruments or software are necessarily the best available for the purpose. 
The system calibrator and DMMs are periodically characterized using the support equipment and NIST reference standards shown in Table 2 and in Fig. 2.

Table 2

Support Equipment

\begin{tabular}{|c|c|}
\hline Function & Support Equipment and NIST Reference Standards \\
\hline $\begin{array}{l}\text { DC voltage } \\
\text { (DCV) }\end{array}$ & $\begin{array}{l}\text { NIST } 10 \mathrm{~V} \text { Josephson array } \\
\text { Wavetek } 491110 \mathrm{~V} \text { zener reference } \\
\text { Fluke } 752 \text { resistive voltage divider }(0.1: 1 \text { to } 100: 1)\end{array}$ \\
\hline $\begin{array}{l}\text { DC current } \\
\text { (DCI) }\end{array}$ & $\begin{array}{c}\text { NIST standard resistors }(0.1 \Omega \text { to } 100 \mathrm{M} \Omega) \\
\text { System DMM (DCV) }\end{array}$ \\
\hline $\begin{array}{l}\mathrm{DC} \text { resistance } \\
\text { (DCR) }\end{array}$ & $\begin{array}{l}\text { NIST standard resistors } \\
\text { System DMM (RES) }\end{array}$ \\
\hline $\begin{array}{c}\text { AC voltage } \\
(\mathrm{ACV})\end{array}$ & $\begin{array}{c}\text { System calibrator (DCV) } \\
\text { NIST thermal voltage converters }(0.1 \mathrm{~V} \text { to } 1 \mathrm{kV}, 10 \mathrm{~Hz} \text { to } 100 \mathrm{MHz}) \\
\text { Ballantine } 440 \text { and Holt } 12 \mathrm{micropotentiometers} \\
(1 \mathrm{mV} \text { to } 200 \mathrm{mV}, 10 \mathrm{~Hz} \text { to } 30 \mathrm{MHz}) \\
\text { Wavetek } 4920 \text { ac digital voltmeter }(1 \mathrm{mV} \text { to } 200 \mathrm{mV}, 11 \text { tz to } 30 \mathrm{MHz}) \\
\text { NIST DSS-5 Digitally Synthesized Source }(1 \mathrm{mV} \text { to } 7 \mathrm{~V} \text {, dc to } 1 \mathrm{kHz}) \\
\text { Keithley } 181 \text { and } 182 \mathrm{dc} \text { nanovoltmeters } \\
\text { Hewlett Packard } 34420 \mathrm{~A} \text { nanovoltmeters }\end{array}$ \\
\hline $\begin{array}{l}\text { AC current } \\
(\mathrm{ACI})\end{array}$ & $\begin{array}{l}\text { System calibrator }(\mathrm{DCI}) \\
\text { NIST thermal current converters }(2 \mathrm{~mA} \text { to } 20 \mathrm{~A}, 10 \mathrm{~Hz} \text { to } 100 \mathrm{kHz}) \\
\text { NIST DSS-5 } \\
\text { NIST Transconductance Amplifier } \\
\text { NIST ac resistors }(0.1 \Omega \text { to } 100 \mathrm{k} \Omega)\end{array}$ \\
\hline
\end{tabular}

Instruments are controlled using a PC (486 or higher) and a National Instruments GPIB-PCIIA general purpose interface bus (GPIB) interface card.

\subsection{MCS Software}

The systehn software, developed in National İnstruments LabVIEWTM, allows the operator to perform all of the tests needed to characterize the system calibrator and DMMs, store and edit correction files, and set up and perform tests of the instrument under test (IUT). Since the instrumentation is 


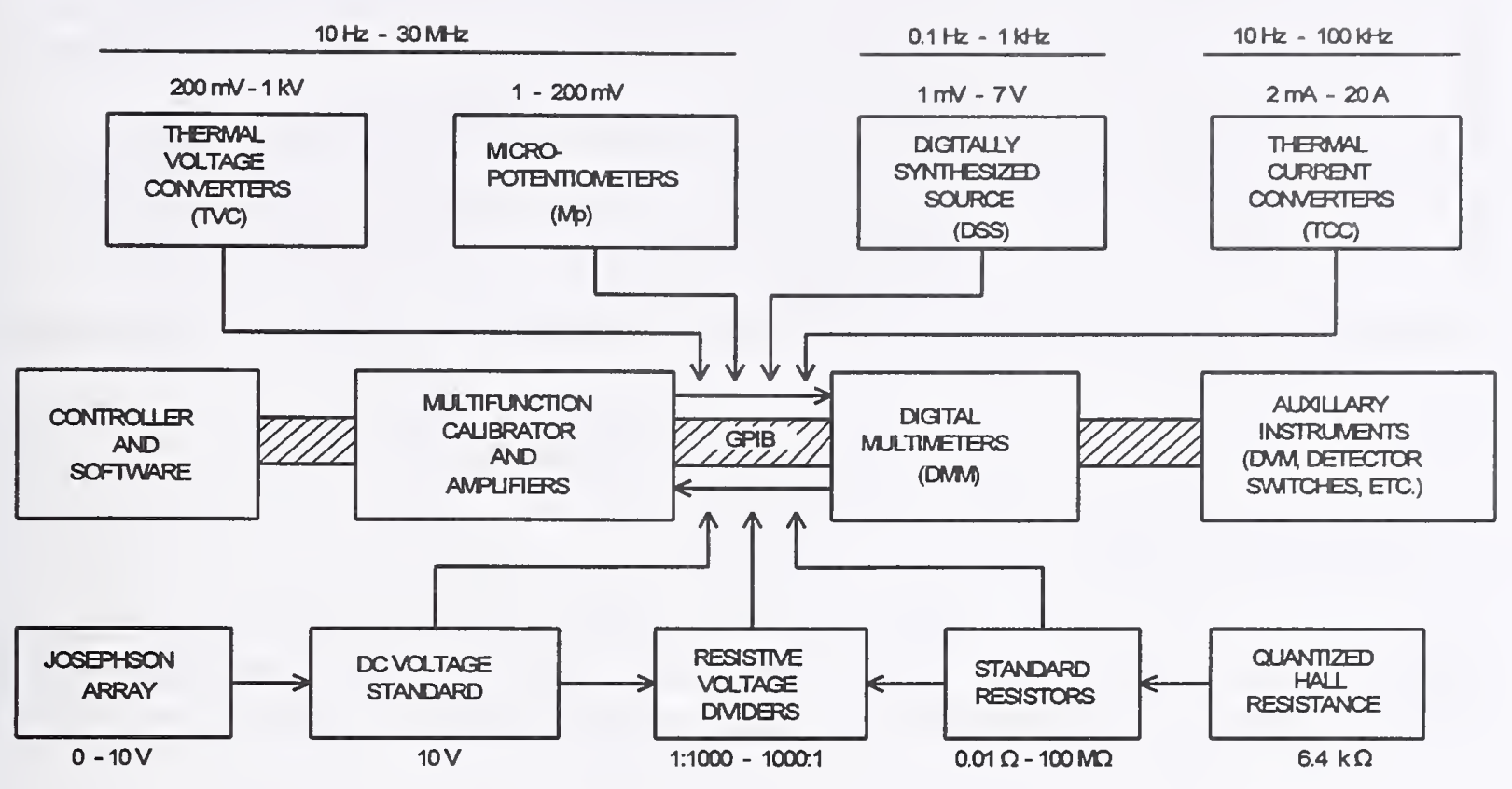

Fig. 2. Block diagram of MCS support equipment.

controlled through the GPIB, most tests can be completely automated, requiring an operator only to change connections between the calibrator and DMM for certain functions. Test data are numerically processed using commercial spreadsheet software. In addition to the software developed at NIST, the MCS also makes use of commercial software to control the 4950 DMM.

Table 3

A list of the software routines available in the MCS

\begin{tabular}{||c|l||}
\hline Title & \multicolumn{1}{|c|}{ Description } \\
\hline DMM cal & $\begin{array}{l}\text { Used to calibrate any of the functions on a test DMM using } \\
\text { the MCS calibrator. }\end{array}$ \\
\hline Calibrator cal & $\begin{array}{l}\text { Used to calibrate any of the functions on a test calibrator } \\
\text { using one of the MCS DMMs. }\end{array}$ \\
\hline Thermal V/I cal & $\begin{array}{l}\text { Used to calibrate the ac voltage and current functions of } \\
\text { DMMs and calibrators using thermal converters. }\end{array}$ \\
\hline DC V/I cal & $\begin{array}{l}\text { Used to calibrate the dc voltage and current functions of the } \\
\text { MCS calibrator and DMMs. }\end{array}$ \\
\hline
\end{tabular}




\begin{tabular}{||c|l||}
\hline DCR & $\begin{array}{l}\text { Used to calibrate the resistance function of the MCS } \\
\text { calibrator and DMMs. }\end{array}$ \\
\hline AC-DC diff & $\begin{array}{l}\text { Used to determine the ac-dc difference of thermal } \\
\text { voltage/current converters and micropotentiometers. }\end{array}$ \\
\hline 4950MTS & $\begin{array}{l}\text { Software that uses a 4950 DMM to test a calibrator, and } \\
\text { store a new set of firmware corrections in Wavetek } \\
\text { calibrators. }\end{array}$ \\
\hline
\end{tabular}

\section{CHARACTERIZING THE MCS}

\subsection{Voltage (DCV)}

A Wavetek $491110 \mathrm{~V}$ zener reference is part of the MCS equipment used to support the DCV function of the system calibrator and DMMs. This instrument is periodically compared to the NIST $10 \mathrm{~V}$ Josephson array [5]. A control chart with the zener reference corrections is shown in Fig. 3.

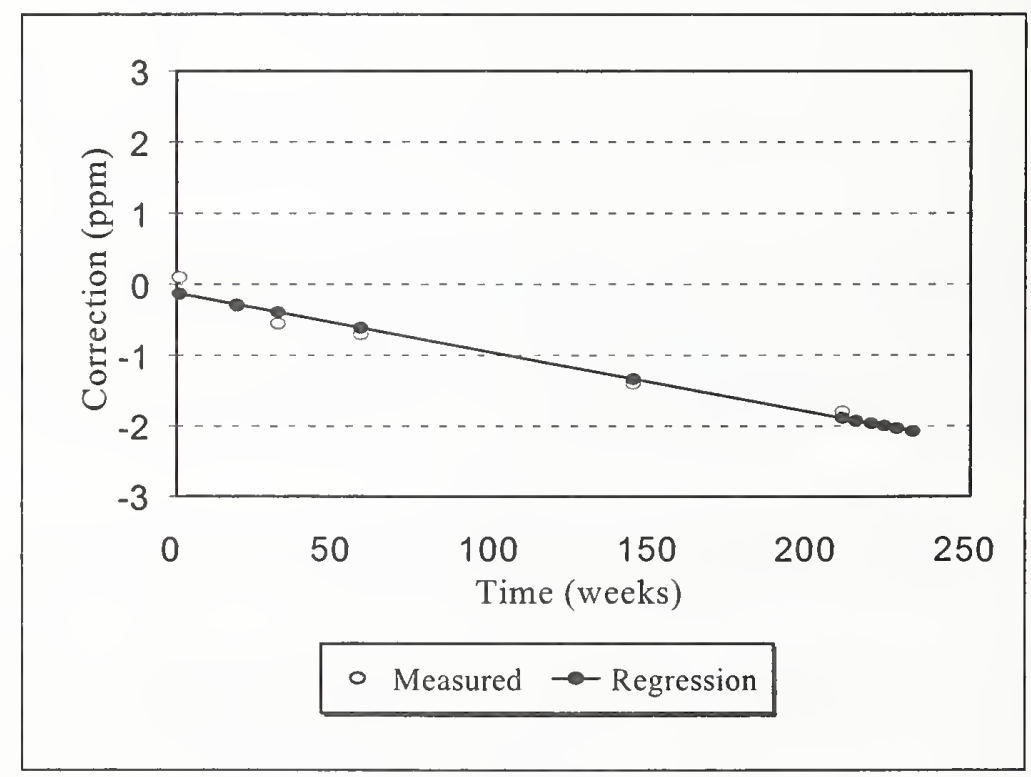

Fig. 3. Control chart with measured and predicted corrections for the zener reference.

Periodically, special resistive dividers, a Fluke 752, and another similar divider designed at NIST, are used to compare five calibrator voltages $(100 \mathrm{mV}, 1 \mathrm{~V}, 10 \mathrm{~V}, 100 \mathrm{~V}$, and $1 \mathrm{kV})$ to the $10 \mathrm{~V}$ zener reference. The dc voltage corrections to the calibrator $C_{c D C V}$ are related to the calibrator setting $S$ and the actual calibrator output voltage $V_{c D C V}$ by:

$$
V_{c D C V}=S\left(1+C_{c D C V}\right) \text {. }
$$


A control chart with selected calibrator corrections is shown in Fig. 4. Over long intervals, calibrator corrections tend to drift linearly with time, so a least-squares fit to the correction time series is performed and a linear equation is used to predict the calibrator correction between calibrations.

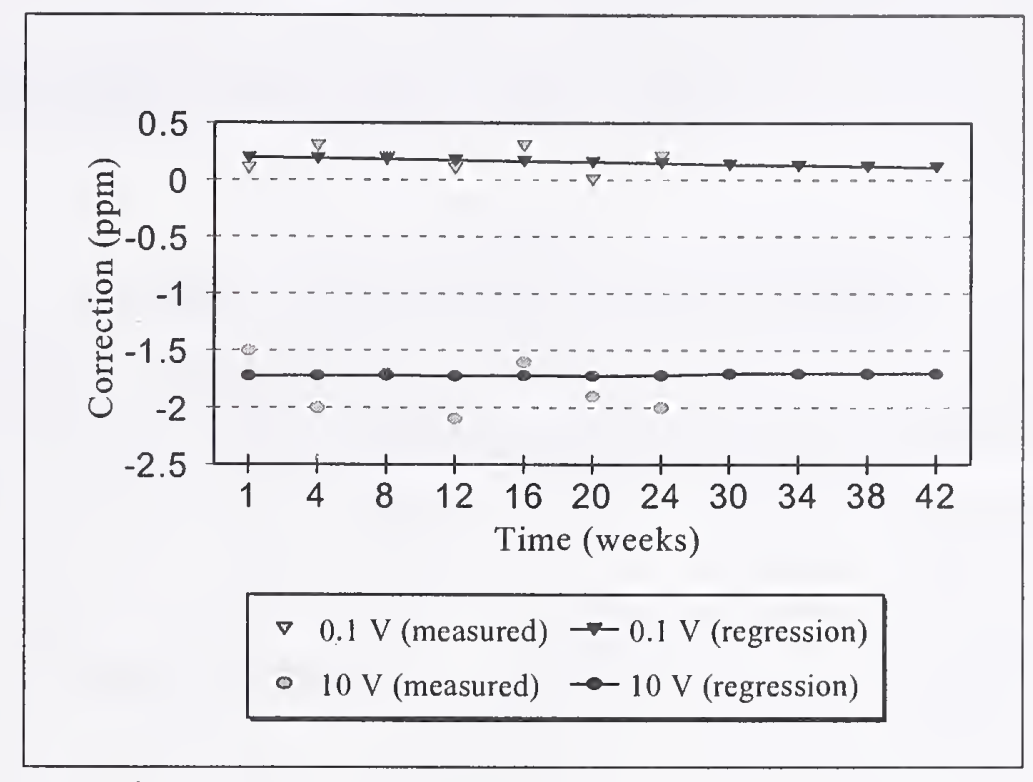

Fig. 4. Control chart with measured and predicted corrections for the MCS calibrator for DCV.

The system DMMs are calibrated at $10 \mathrm{~V}$ directly against the zener reference and at other voltages using the characterized calibrator. The DMM corrections $C_{d D C V}$ are related to the DMM reading $R$ and the true voltage $V_{D C}$ by:

$$
V_{D C}=R\left(1+C_{d D C V}\right)
$$

The system calibrator and DMMs rely on an internal zener voltage reference and timing to generate and measure voltage. The calibrator uses a scaling technique known as time-division-multiplexing, while the DMMs employ multislope integrating analog-to-digital converters. Both techniques are capable of excellent linearity. The linearity of one of the system DMMs has been shown to be better than 1 part in $10^{7}$ of full scale between $1 \mathrm{~V}$ to $10 \mathrm{~V}$ using the Josephson array [5]. The linearity of other voltage ranges is measured using a calibrated DMM and resistive divider.

For both the calibrator and DMMs, calibration at full scale and $10 \%$ of full scale in each range is generally adequate to characterize the full range. The system software linearly interpolates between calibration points to compute calibrator corrections over the full range ( $>10^{7}$ discrete voltages). These software corrections are applied during the test of a customer's DMM. DMM corrections are processed in a similar manner and applied during the test of a customer's calibrator.

The uncertainty of DCV measurements performed using the MCS depends on uncertainties computed during the test (Type A) and uncertainties associated with the calibration of the MCS (Type B). A 
description of these uncertainty types and methods of combining them is given in Section 5 and in reference [6].

The Type B standard uncertainties of the MCS calibrator for DCV are given in Table 4. These figures include uncertainties associated with the DCV support equipment described in Table 2. The uncertainties in Table 4 are for the set of points where the MCS is routinely calibrated and monitored (Calibrated Points) and for all other points within the range (Full Range) where corrections are interpolated estimates.

\section{Table 4}

MCS Type B Standard Uncertainties for DCV

\begin{tabular}{||c|c|c||}
\hline Voltage Range & Calibrated Points & Full Range \\
\hline $1 \mathrm{mV}$ to $100 \mathrm{mV}$ & $5 \mu \mathrm{V} / \mathrm{V}+1 \mu \mathrm{V}$ & $10 \mu \mathrm{V} / \mathrm{V}+1 \mu \mathrm{V}$ \\
\hline $100 \mathrm{mV}$ to $1 \mathrm{~V}$ & $2 \mu \mathrm{V} / \mathrm{V}+1 \mu \mathrm{V}$ & $4 \mu \mathrm{V} / \mathrm{V}+1 \mu \mathrm{V}$ \\
\hline $1 \mathrm{~V}$ to $10 \mathrm{~V}$ & $1 \mu \mathrm{V} / \mathrm{V}+1 \mu \mathrm{V}$ & $2 \mu \mathrm{V} / \mathrm{V}+1 \mu \mathrm{V}$ \\
\hline 10 to $100 \mathrm{~V}$ & $2 \mu \mathrm{V} / \mathrm{V}$ & $4 \mu \mathrm{V} / \mathrm{V}$ \\
\hline $100 \mathrm{~V}$ to $1 \mathrm{kV}$ & $3 \mu \mathrm{V} / \mathrm{V}$ & $6 \mu \mathrm{V} / \mathrm{V}$ \\
\hline
\end{tabular}

\subsection{Current (DCI)}

The DCI function of the MCS calibrator and DMMs is periodically calibrated by applying various calibrator currents to a set of NIST reference, four-terminal resistors and measuring the voltage across the resistors using a system DMM. The set of reference resistors consists of values between $0.1 \Omega$ and $1 \mathrm{M} \Omega$ that are maintained in oil and air baths with a temperature control of $\pm 0.1^{\circ} \mathrm{C}$, and are periodically calibrated against the NIST resistance standards [7].

To measure the influence of compliance voltage, calibrator currents are measured with the following burdens:

a. reference resistor only,

b. reference resistor and each system DMM,

c. each system DMM only.

The compliance voltage is measured for each burden and the current differences vs compliance voltage are plotted. If there is a significant difference, additional burden measurements are made to cover the expected range of customer's DMM burdens. Linear interpolation between data points is generally adequate to correct the calibrator current. 
The dc current corrections to the calibrator $C_{C D C I}$ are related to the calibrator setting $S$ and the actual calibrator output current $I_{C D C I}$ by:

$$
I_{c D C I}=S\left(1+C_{c D C I}\right)
$$

The system DMMs are also calibrated at various currents by this procedure. The DMM corrections $C_{d D C I}$ are related to the DMM reading $R$ and the true current $I_{D C}$ by:

$$
I_{D C}=R\left(1+C_{d D C I}\right)
$$

A control chart with selected DCI calibrator corrections is shown in Fig. 5. DCI corrections tend to drift linearly with time, so a least squares fit to the correction time series is performed and a linear equation is used to predict the calibrator correction between calibrations. The system software also linearly interpolates between calibration points to compute corrections over the full range. As with $\mathrm{DCV}$, software corrections are applied during DMM and calibrator tests.

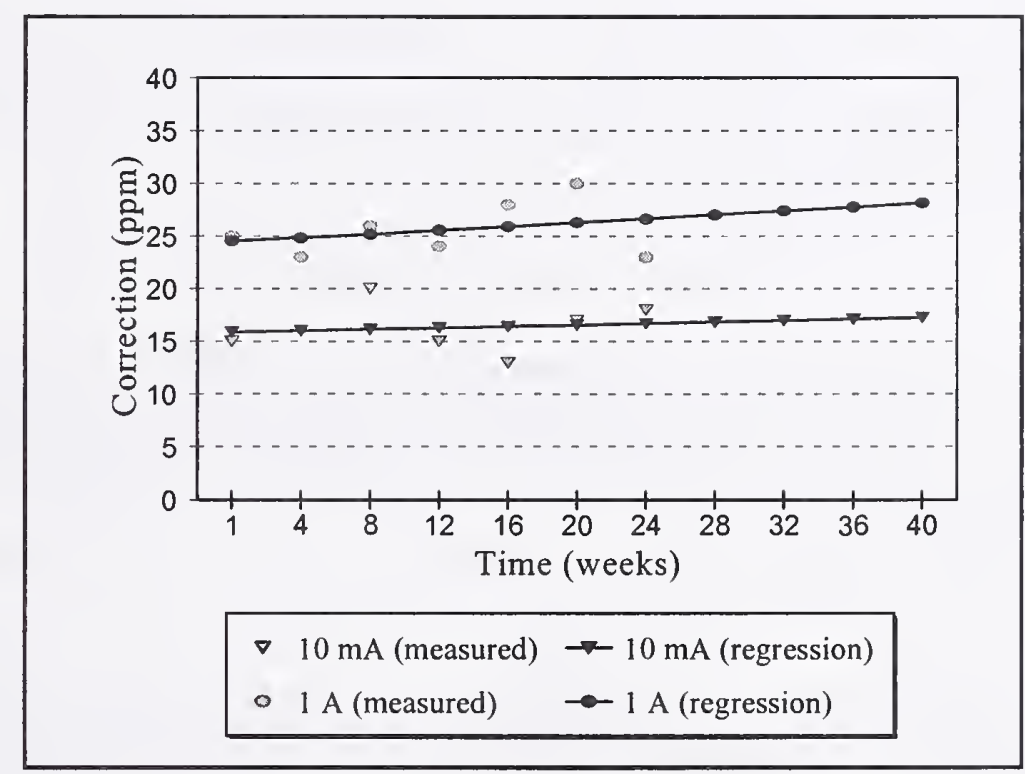

Fig. 5. Control chart with measured and predicted corrections for the MCS calibrator for DCI.

Measurements are performed at cardinal currents between $1 \mu \mathrm{A}$ and $10 \mathrm{~A}$. Measurements at other currents indicate that, for the calibrator and DMMs, the current linearity is generally as good or better than the current stability. However, for measurement at other than the calibrated points, the MCS corrections are interpolated estimates and uncertainties are somewhat larger. As with DCV, the uncertainty of DCI measurements performed using the MCS depend on Type A and Type B standard uncertainties. The Type B standard uncertainties of the MCS calibrator for DCI (which include the uncertainties of the DCI support equipment described in table 2) are given in Table 5. 
Table 5

MCS Type B Standard Uncertainties for DCI

\begin{tabular}{||c|c|c|}
\hline Current Range & Calibrated Points & Full Range \\
\hline $1 \mu \mathrm{A}$ to $1 \mathrm{~mA}$ & $20 \mu \mathrm{A} / \mathrm{A}+10 \mathrm{nA}$ & $40 \mu \mathrm{A} / \mathrm{A}+10 \mathrm{nA}$ \\
\hline $1 \mathrm{~mA}$ to $10 \mathrm{~mA}$ & $15 \mu \mathrm{A} / \mathrm{A}$ & $30 \mu \mathrm{A} / \mathrm{A}$ \\
\hline $10 \mathrm{~mA}$ to $100 \mathrm{~mA}$ & $10 \mu \mathrm{A} / \mathrm{A}$ & $20 \mu \mathrm{A} / \mathrm{A}$ \\
\hline $100 \mathrm{~mA}$ to $1 \mathrm{~A}$ & $20 \mu \mathrm{A} / \mathrm{A}$ & $40 \mu \mathrm{A} / \mathrm{A}$ \\
\hline $1 \mathrm{~A}$ to $10 \mathrm{~A}$ & $25 \mu \mathrm{A} / \mathrm{A}$ & $50 \mu \mathrm{A} / \mathrm{A}$ \\
\hline
\end{tabular}

\subsection{Resistance (DCR)}

The DCR function of the MCS calibrator and DMMs is periodically calibrated against the set of NIST reference resistors described earlier. Each reference resistor is measured by the system DMMs using the 4-wire DCR function. The dc resistance corrections to the DMM $C_{d D C R}$ are related to the DMM reading $R$ and the true dc resistance $R_{D C}$ by:

$$
R_{D C}=R\left(1+C_{d D C R}\right)
$$

Once the DMMs are calibrated, they are used to measure the set of resistors in the system calibrator. The corrections to the calibrator resistors are based on the average of values assigned by the system DMMs. The dc resistance corrections to the calibrator $C_{c D C R}$ are related to the calibrator setting $S$ and the actual calibrator dc resistance $R_{c D C R}$ by:

$$
R_{c D C R}=S\left(1+C_{c D C R}\right) .
$$

A control chart with selected DCR calibrator corrections is shown in Fig. 6. DCR corrections also tend to drift linearly with time, so a least squares fit to the correction time series is performed and a linear equation is used to predict the calibrator correction between calibrations. The system software also linearly interpolates between calibration points to compute corrections over the full range (DMMs only). As with other functions, software corrections are applied during DMM and calibrator tests.

Measurements are performed at nominal decade resistance values from $0.1 \Omega$ to $100 \mathrm{M} \Omega$ using the DMMs. Decade resistance values between $1 \Omega$ and $10 \mathrm{M} \Omega$ are available on the system calibrator.

Other than decade values may be measured using the system DMMs, which demonstrate resistance linearity as good or better than resistance stability. However, for measurement at other than the calibrated points, the MCS corrections are interpolated estimates and uncertainties are somewhat larger. The Type B standard uncertainties of the MCS DCR (which include the uncertainties of the 
DCR support equipment described in table 2) are given in Table 6.

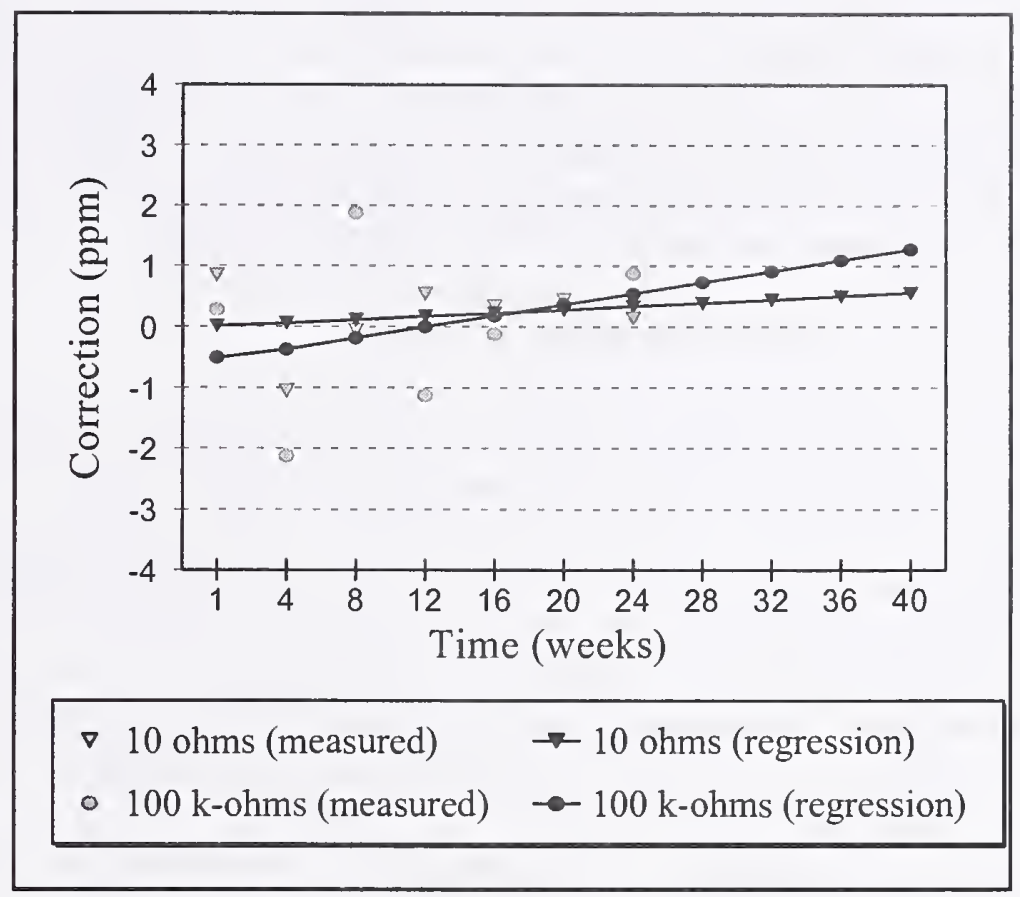

Fig. 6. Control chart with measured and predicted corrections for the MCS calibrator for DCR.

Table 6

MCS Type B Standard Uncertainties for DCR

\begin{tabular}{|c|c|c|}
\hline Resistance Range & Calibrated Points & Full Range \\
\hline $1 \Omega$ & $20 \mu \Omega / \Omega$ & $60 \mu \Omega / \Omega$ \\
\hline $10 \Omega$ & $10 \mu \Omega / \Omega$ & $30 \mu \Omega / \Omega$ \\
\hline $100 \Omega$ & $6 \mu \Omega / \Omega$ & $18 \mu \Omega / \Omega$ \\
\hline $1 \mathrm{k} \Omega$ & $3 \mu \Omega / \Omega$ & $9 \mu \Omega / \Omega$ \\
\hline $100 \Omega$ & $3 \mu \Omega / \Omega$ & $9 \mu \Omega / \Omega$ \\
\hline $100 \mathrm{k} \Omega$ & $4 \mu \Omega / \Omega$ & $12 \mu \Omega / \Omega$ \\
\hline $1 \mathrm{M} \Omega$ & $5 \mu \Omega / \Omega$ & $15 \mu \Omega / \Omega$ \\
\hline $10 \mathrm{M} \Omega$ & $20 \mu \Omega / \Omega$ & $60 \mu \Omega / \Omega$ \\
\hline $100 \mathrm{M} \Omega$ & $30 \mu \Omega / \Omega$ & $90 \mu \Omega / \Omega$ \\
\hline
\end{tabular}




\subsection{AC Voltage (ACV)}

The low-frequency ACV function of the MCS calibrator and DMMs is periodically calibrated using a multirange thermal voltage converter (TVC) that has been calibrated against a set of NIST reference TVCs, micropotentiometers, and a calculable DSS [8] . The ac-dc differences of these support instruments are ultimately referenced to a set of characterized TVCs that are the NIST standards for ac-dc difference [9]. The test procedures for characterizing the system calibrator and DMMs for ACV are more complex than the other functions and will be described in detail.

\subsubsection{Voltages from $1 \mathrm{mV}$ to $1 \mathrm{kV}$ from $10 \mathrm{~Hz}$ to $1 \mathrm{MHz}$}

The multirange TVC is connected to the MCS calibrator and to the DMM (both set to the ACV mode) as shown in Fig. 7. The nominal ac voltage $V$ at frequency $f_{l}$ is programmed and the output emf of the TVC, $e_{a}$ is measured using the dc digital voltmeter (DVM). The calibrator function is switched to $+\mathrm{DCV}$ and the amplitude is programmed to $+V$. The calibrator voltage is adjusted to $V_{+d l}$ to bring the TVC emf $e_{+d l}$ to within $\pm t$ of $e_{a}$. [The operator selectable tolerance $t$ is typically between 10 $\mu \mathrm{V} / \mathrm{V}$ and $50 \mu \mathrm{V} / \mathrm{V}$.] The calibrator is switched back to ACV and the TVC emf $e_{a 1}$ and the DMM $\mathrm{ACV}$ reading $R_{a l}$ are recorded. The calibrator is then switched to -DCV and adjusted to $V_{-d l}$ to bring the TVC emf $e_{-d l}$ to within $\pm t$ of $e_{a l}$. The above procedure is repeated for frequencies $f_{2}$ through $f_{i}$

The TVC is disconnected, the calibrator is switched to $\mathrm{ACV}$, frequencies $f_{1}$ through $f_{i}$ are set at the same nominal voltage $V$, and the DMM readings $R_{b l}$ through $R_{b i}$ are recorded.

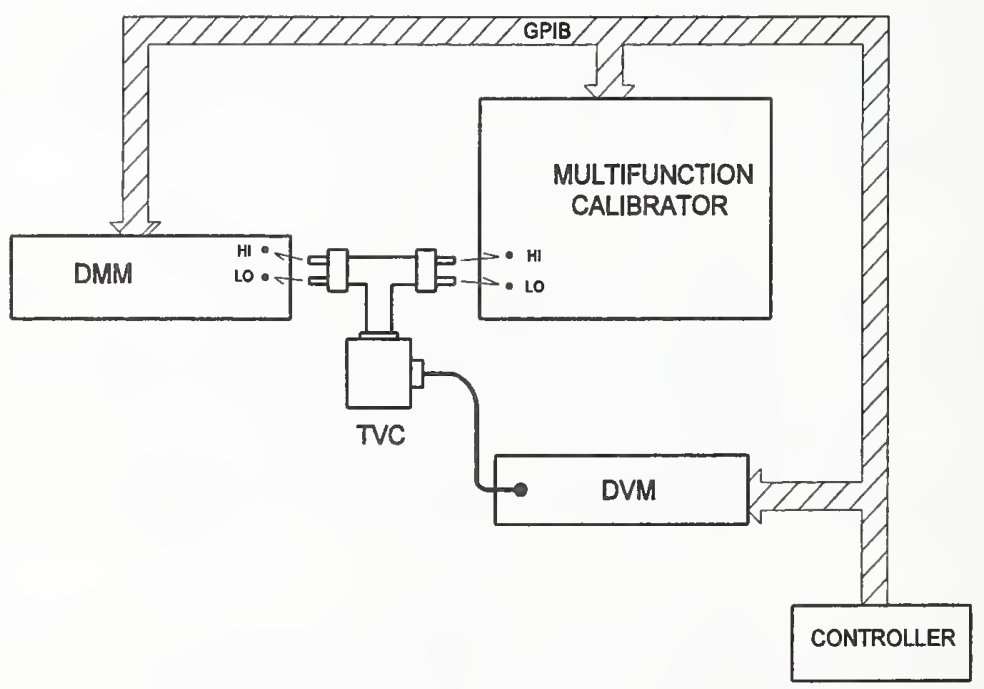

Fig. 7. Setup for characterizing the ACV function of the MCS using a multirange TVC. 
The calibrator correction for each test voltage at frequency $f_{i}$ is described by:

$$
C_{c A C V i}=\left(V_{d i}-V\right) / V_{d i}+\left(e_{a i}-e_{d i}\right) /\left(n e_{d i}\right)+D_{i}+C_{c D C V}
$$

where $V_{d i}=\left(V_{+d i}-V_{-d i}\right) / 2$ ane. dc voltage

$e_{d i}=\left(e_{+d i}+e_{-d i}\right) / 2$ ave. TVC emf with $\pm \mathrm{DCV}$ applied

$n=$ the TVC power coefficient at the nominal voltage

$D_{i}=$ the ac-dc difference of the TVC at the nominal voltage at $f_{i}$

$C_{c D C V}=$ the average calibrator DCV correction.

The DMM correction for each test voltage at frequency $f_{i}$ is given by:

$$
C_{d A C V i}=\left(V\left(1+C_{c A C V i}\right)-R_{a i}\right) / R_{a i}
$$

where $R_{a i}=$ the DMM reading of the test voltage at $f_{i}$.

Notes: $i . \quad$ The above procedure is designed to allow the MCS to be calibrated using the reference TVCs as well as the multirange TVC. By driving the dc voltage to match the TVC output when ac voltage is applied, the importance of an accurate knowledge of the TVC power coefficient $n$ is minimized by minimizing the numerator in the second term of (7). For the reference TVCs, this coefficient varies between 1.6 and 2 as a function of the test voltage and must be measured at each voltage. The multirange TVC has a nominal power coefficient of 1 , which is relatively insensitive to the test voltage, so the tolerance t may be increased to reduce test time.

ii. $\quad$ The reference TVC time constants are typically $1 \mathrm{~s}$ to $2 \mathrm{~s}$; therefore, a wait period of up to $30 \mathrm{~s}$ is required before recording the TVC emf. To minimize the effects of drift, it is important that all of the wait periods are the same for a particular set of measurements. The multirange TVC settles in about $10 \mathrm{~s}$ and has a low drift rate so timing is not as critical.

iii. It is important that the dead time in switching from the $A C V$ to the $D C V$ functions is minimized. For the highest accuracy using reference TVCs, a switch and auxiliary supply are used to keep the TVC energized while the calibrator is switching between functions. The multirange TVC is less sensitive to switching time.

$i v$. The dc DVM should be able to resolve the TVC emf to within $\pm 1 \mu V / V$. This resolution corresponds to several $n V$ for the reference TVCs (which have output emfs from $2 \mathrm{mV}$ to $10 \mathrm{mV}$ ) and several $\mu \mathrm{V}$ for the multirange TVC (which has a full scale output of about $2 \mathrm{~V}$ ).

$v$. Depending on the random error of the measurements, an actual calibration consists of from 1-10 repeats of the described procedure.

As the test frequency increases the calibrator becomes more sensitive to the load imposed by the TVC and the test DMM. Therefore, to obtain the lowest uncertainties, the calibrator must be characterized for each DMM type using the procedure described above. The second set of DMM readings $R_{b i}$ is 
used to generate unique corrections $C_{C A C V i(X)}$ for all DMMs of that type (type-X DMMs for this example). These corrections apply only when a type-X DMM is connected to the calibrator using the same connectors and cables that were used to obtain the set of $R_{b i}$ readings. The unique set of calibrator corrections for each DMM type are given by:

$$
C_{C A C V i(X)}=C_{c A C V i}+C_{d i(X)} \text {. }
$$

where $C_{d i(X)}=\left(R_{b i(X)}-R_{a i(X)}\right) / V_{i}$ represents the additional correction needed to compensate for the difference between the calibrator output voltage (programmed to $V_{i}$ ) with the TVC and type-X DMM connected and with only the type-X DMM connected.

\subsubsection{Voltages from $1 \mathrm{mV}$ to $250 \mathrm{mV}$ from $10 \mathrm{~Hz}$ to $1 \mathrm{MHz}$}

A reference micropotentiometer ( $\mu$ pot) is connected to the system calibrator output and a DMM is connected to its output as shown in Fig. 8. The calibrator is set to the ACV function at $1 \mathrm{kHz}$ and its voltage is adjusted until the DMM reading $R_{r 0}$ is within $\pm \mathrm{t}$ of the test voltage $\mathrm{V}$. The DMM reading $R_{r 0}$ and the $\mu$ pot output emf $e_{r 0}$ are recorded. The calibrator frequency is programmed to $f_{l}$ (the first test frequency), the calibrator voltage is adjusted until the $\mu$ pot emf $e_{a l}$ is within $\pm t$ of $e_{r 0}$, and the DMM reading $R_{a l}$ is recorded. The calibrator is programmed to $1 \mathrm{kHz}$, the calibrator voltage is adjusted until the nominal test voltage $V \pm t$ is read by the DMM, and its reading $R_{r l}$ and the $\mu$ pot emf $e_{r l}$ are recorded. The procedure is repeated for frequencies $f_{2}$ through $f_{i}$ interleaving a $1 \mathrm{kHz}$ measurement between measurements at each test frequency.

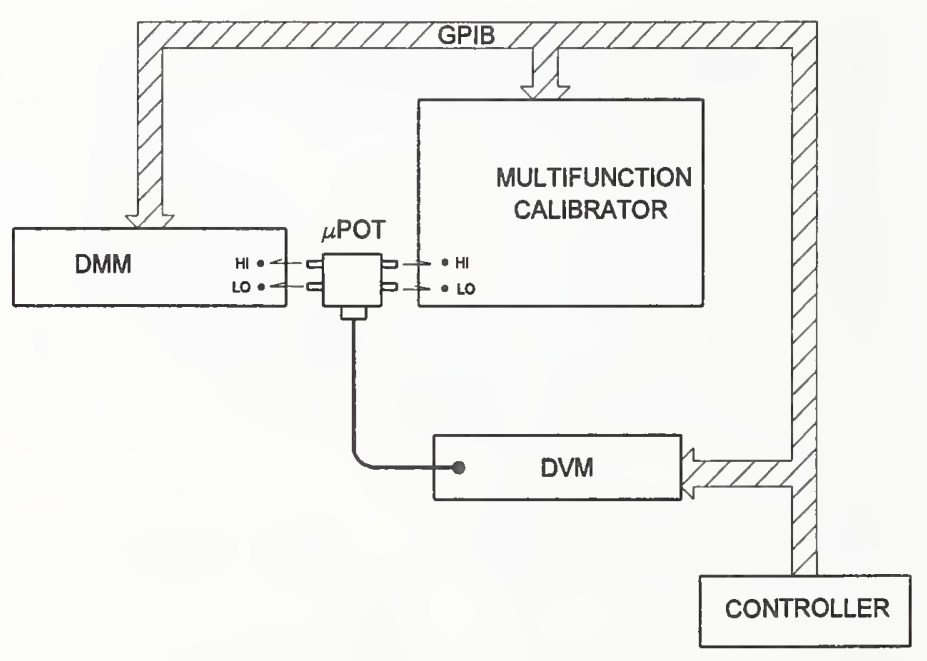

Fig. 8. Setup for characterizing the ACV function of the MCS using a $\mu$ pot.

The $\mu$ pot is removed, the DMM is connected directly to the calibrator output, frequencies $f_{l}$ through $f_{i}$ are set at the test voltage $V$, and the DMM readings $R_{b l}$ through $R_{b i}$ are recorded. 
The DMM corrections for each test voltage at frequency $f_{i}$ is described by the following relationship:

$$
C_{d i}=\left(R_{R i}-R_{a i}\right) / R_{R i}+\left(e_{a i}-e_{R i}\right) /\left(n e_{R i}\right)+D_{i}+C_{d R}
$$

where $R_{R i}=\left(R_{r(i-1)}+R_{r i}\right) / 2$ ave. $1-\mathrm{kHz}$ reading

$e_{R i}=\left(e_{r(i-I)}+e_{r i}\right) / 2$ ave. $\mu$ pot emf with $1 \mathrm{kHz}$ applied

$n=$ the $\mu$ pot power coefficient at output voltage $V$

$D_{i}=$ the ac $1-\mathrm{kHz}$ difference of the $\mu$ pot at output $V$ at $f_{i}$

$C_{d R}=$ the DMM 1-kHz correction.

The calibrator correction is given by:

$$
C_{c i A}=\left(R_{b i}\left(1+C_{d i}\right)-V\right) / V
$$

where $R_{b i}=$ the DMM reading of the test voltage at $f_{i}$.

\subsubsection{Voltage from $250 \mathrm{mV}$ to $7 \mathrm{~V}$ from $10 \mathrm{~Hz}$ to $30 \mathrm{MHz}$}

Measurements are performed using the calibrator $50-\Omega$ wideband output port. Special $50 \Omega$ TVCs, calibrated out to $30 \mathrm{MHz}$, are used to measure the amplitude flatness of the calibrator using a technique similar to that described in 3.4.1, except the calibrator is left on the ACV function and each test frequency is referred back to $1 \mathrm{kHz}$.

A $50 \Omega$ TVC is connected to the wideband output of the MCS calibrator and to a wideband DMM in a similar manner as shown in Fig. 7. The nominal voltage $V$ at frequency $f_{l}$ is programmed and the TVC emf $e_{a}$ is measured using the dc DVM. The calibrator frequency is set to $1 \mathrm{kHz}$ and its amplitude is adjusted to $V_{r 0}$ to bring the TVC emf $e_{r 0}$ to within $\pm t$ of $e_{a}$. The calibrator frequency is set to $f_{l}$ and the TVC emf $e_{a l}$ and the DMM reading $R_{a l}$ are recorded. The calibrator is reprogrammed to $1 \mathrm{kHz}$ and adjusted to $V_{r l}$ to bring the TVC emf $e_{r l}$ to within $\pm t$ of $e_{a l}$. The above procedure is repeated for frequencies $f_{2}$ through $f_{i}$.

The TVC is disconnected, frequencies $f_{I}$ through $f_{i}$ are set at the same nominal voltage $V$, and the DMM readings $R_{b I}$ through $R_{b i}$ are recorded.

The calibrator correction for each test voltage at frequency $f_{i}$ is described by:

$$
C_{c A C V i}=\left(V_{R i}-V\right) / V+\left(e_{a i}-e_{d i}\right) /\left(n e_{d i}\right)+D_{i}+C_{c R}
$$

where $V_{R i}=\left(V_{r(I-I)}-V_{-r i}\right) / 2$ ave. $1-\mathrm{kHz}$ voltage $\}$

$e_{d i}=\left(e_{+d i}+e_{-d i}\right) / 2$ \{ave. $1-\mathrm{kHz}$ TVC emf

$n=$ the TVC power coefficient at $V$

$D_{i}=$ the ac-dc difference of the TVC at $V$ at $f_{i}$

$C_{c R}=$ the calibrator $1 \mathrm{kHz}$ correction at $V$. 
The DMM correction for each test voltage at frequency $f_{i}$ is then given by:

$$
C_{d A C V i}=\left(V\left(l+C_{c A C V i}\right)-R_{a i}\right) / R_{a i},
$$

where $R_{a i}=$ the DMM reading of the test voltage at $f_{i}$.

\subsubsection{Voltages from $1 \mathrm{mV}$ to $1 \mathrm{kV}$ from $0.01 \mathrm{~Hz}$ to $1 \mathrm{kHz}$}

A programmable digitally synthesized source (DSS) developed at NIST is employed in place of the system calibrator to perform high accuracy, low-frequency tests of DMMs. The DSS synthesizes a staircase approximation of a sine wave using a sine look-up table and a precision digital-to-analog converter (DAC). Output voltages are programmable between $1 \mathrm{mV}$ and $7 \mathrm{~V}$ (for higher voltages an external dc-coupled amplifier is used). A DMM (on its DCV function) is used to measure the dc voltage of each of the steps in the approximation. The rms value of the output voltage $V_{s}$ is computed by this step calibration:

$$
V_{s}=\left(\sum v_{i}^{2} / N\right)^{1 / 2},
$$

where $v_{i}=$ the dc voltages of the steps

$N=$ the number of step per period.

The frequency response rms error of the synthesized signal is measured between $20 \mathrm{~Hz}$ and $1 \mathrm{kHz}$ using a calibrated multirange TVC. Below $20 \mathrm{~Hz}$, it is assumed that the rms value remains constant to within $\pm 2 \mu \mathrm{V} / \mathrm{V}$. At $7 \mathrm{~V}$, the frequency response out to $1 \mathrm{kHz}$ is flat to within $\pm 5 \mu \mathrm{V} / \mathrm{V}$. This performance degrades at lower voltages; however, even at $1 \mathrm{mV}$, the DSS may be treated as an ac calibrator with zero correction below $20 \mathrm{~Hz}$. DMMs calibrated using the DSS are assigned corrections $C_{d A C V i}$ by:

$$
C_{d A C V i}=\left(V_{s}\left(1+C_{D S S i}\right)-R_{b i}\right) / R_{b i},
$$

where $R_{b i}=$ the DMM reading at frequency $f_{i}$

$C_{D S S i}=$ the DSS correction to $V_{s}$ at frequency $f_{i}$.

Control charts for the ACV function corrections of the system calibrator and DMMs are quite complex covering voltage, frequency, and DMM type. A sample chart for the ACV calibrator corrections at $10 \mathrm{~V}$ at $10 \mathrm{kHz}$ is shown in Fig. 9. ACV corrections are less predictable than the DCV corrections; however, until the drift patterns are better understood, a least squares linear fit to the correction time series is performed and a linear equation is used to predict the calibrator correction between calibrations. The system software also linearly interpolates between calibration points to compute corrections over the full range. Specific software corrections for the DMM type being tested are applied where possible and all interconnection parameters are specified. In a similar manner, when a calibrator is tested using a system DMM, the DMM type and all interconnection parameters are specified. Measurements are performed at a specific set of voltages and frequencies from $1 \mathrm{mV}$ to $1 \mathrm{kV}$ and $0.1 \mathrm{~Hz}$ to $30 \mathrm{MHz}$. Measurements can be made at other than the calibrated points; 
however, because the corrections at these points are interpolated estimates, the MCS uncertainties are somewhat larger. The Type B standard uncertainties of the MCS ACV function are given in Table 7.

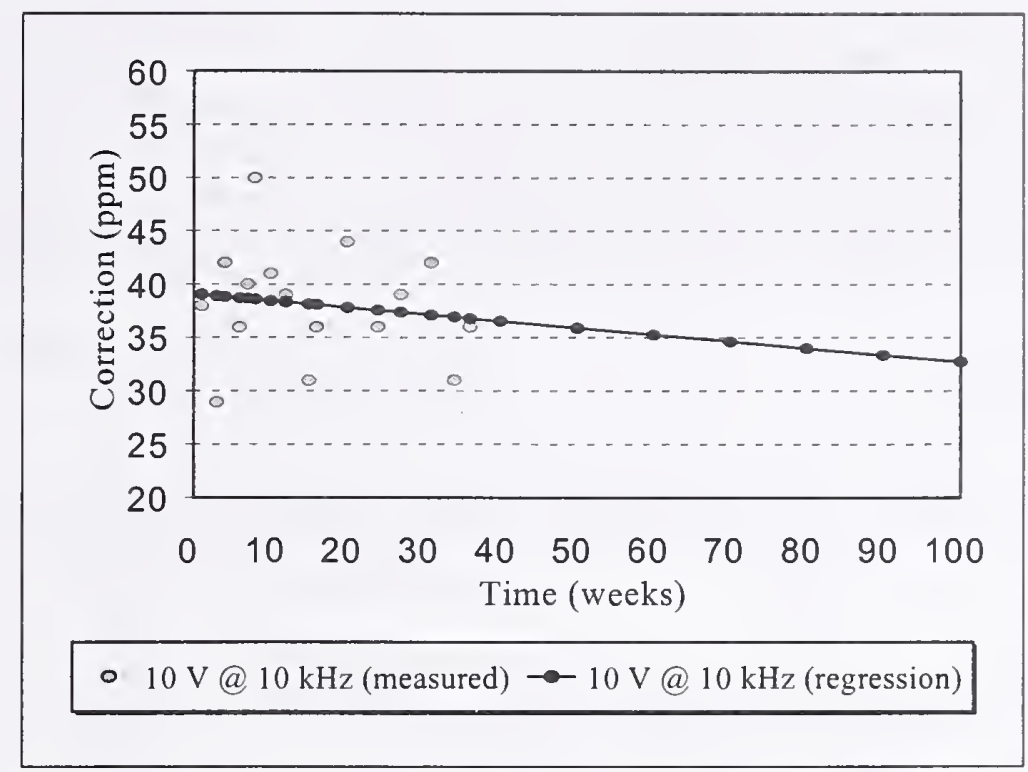

Fig. 9. Control chart with measured and predicted corrections for the MCS calibrator at $10 \mathrm{~V}$ and $10 \mathrm{kHz}$.

Table 7

MCS Type B Standard Uncertainties for ACV

\begin{tabular}{||c|c|c||}
\hline Voltage Range & Calibrated Points & Full Range \\
\hline $1 \mathrm{mV}$ to $10 \mathrm{mV}$ & $(10 / \mathrm{v})(70+\mathrm{f}) \mu \mathrm{V} / \mathrm{V}$ & $(10 / \mathrm{v})(200+\mathrm{f}) \mu \mathrm{V} / \mathrm{V}$ \\
\hline $10 \mathrm{mV}$ to $100 \mathrm{mV}$ & $(70+\mathrm{f} / 2) \mu \mathrm{V} / \mathrm{V}$ & $(200+\mathrm{f} / 2) \mu \mathrm{V} / \mathrm{V}$ \\
\hline $100 \mathrm{mV}$ to $500 \mathrm{mV}$ & $(20+\mathrm{f} / 5) \mu \mathrm{V} / \mathrm{V}$ & $(60+\mathrm{f} / 5) \mu \mathrm{V} / \mathrm{V}$ \\
\hline $500 \mathrm{mV}$ to $100 \mathrm{~V}$ & $(10+\mathrm{f} / 10) \mu \mathrm{V} / \mathrm{V}$ & $(30+\mathrm{f} / 10) \mu \mathrm{V} / \mathrm{V}$ \\
\hline $100 \mathrm{~V}$ to $1 \mathrm{kV}$ & $(20+\mathrm{f} / 5) \mu \mathrm{V} / \mathrm{V}$ & $(60+\mathrm{f} / 5) \mu \mathrm{V} / \mathrm{V}$ \\
\hline
\end{tabular}

Where $\mathrm{v}=$ test voltage in $\mathrm{mV}$ and $\mathrm{f}=$ test frequency in kilohertz.

\subsection{AC Current (ACI)}

The ACI function of the MCS calibrator and DMMs is periodically calibrated against a set of reference thermal current converters (TCCs), ac shunts, and a calculable DSS. The ac-dc differences of these support instruments are ultimately referenced to a set of characterized TCCs that are the NIST standards for ac-dc difference [10]. The test procedures for characterizing the system calibrator and DMMs for ACI are also described in detail. 


\subsubsection{Currents from $2 \mathrm{~mA}$ to $10 \mathrm{~A}$ from $10 \mathrm{~Hz}$ to $100 \mathrm{kHz}$}

The reference TCC is connected to the system calibrator and DMM (both set to the ACI function) as shown in Fig. 10. The calibrator is programmed for the nominal current $I$ at frequency $f_{l}$ and the TCC output emf $e_{a}$ is measured by the dc DVM. The calibrator function is switched to +DCI and programmed to $+I$. The calibrator current is adjusted to $I_{+d l}$ to bring the TCC emf $e_{+d l}$ to within $\pm t \mu \mathrm{V} / \mathrm{V}$ of $e_{a}$. The calibrator is switched back to ACI, the TCC emf $e_{a l}$ and the DMM ACI reading $R_{a l}$ are recorded. The calibrator is then switched to $-\mathrm{DCI}$ and the negative polarity dc current is adjusted

to $I_{-d l}$ to bring the TCC emf to within $\pm t \mu \mathrm{V} / \mathrm{V}$ of $e_{a l}$. The above procedure is repeated for frequencies $f_{2}$ through $f_{i}$.

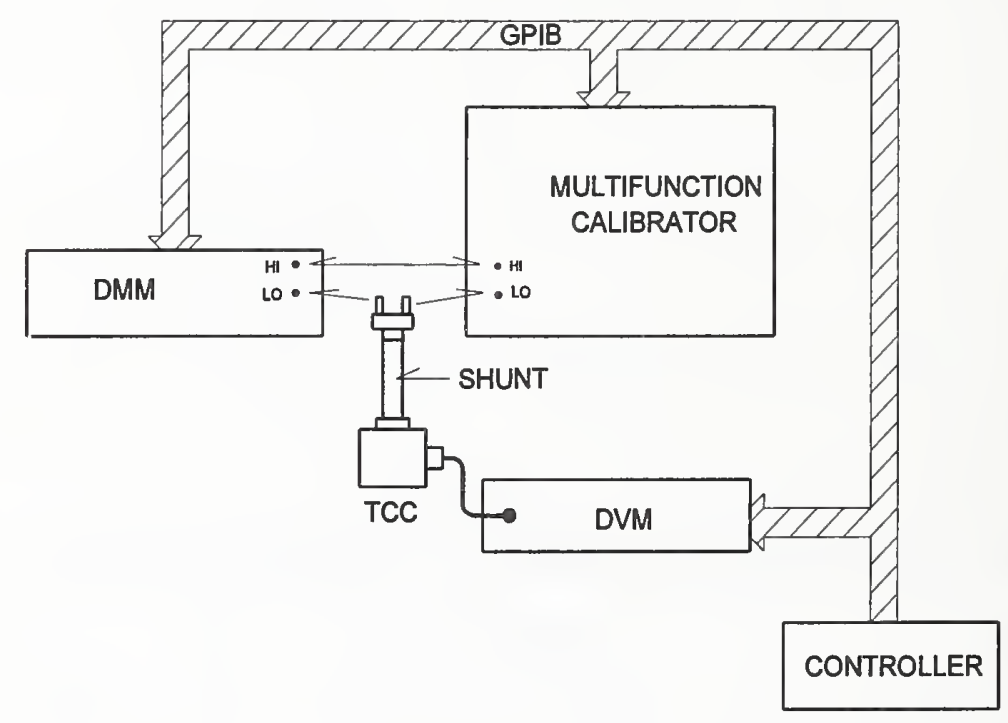

Fig. 10. Setup for characterizing ACI function of MCS calibrator using a TCC.

The TCC is removed, the calibrator is switched to ACI, frequencies $f_{l}$ through $f_{i}$ are set at the same nominal current $I$, and the DMM readings $R_{b l}$ through $R_{b i}$ are recorded. The calibrator correction at each test current at frequency $I$ is described by:

$$
C_{c A C l i}=\left(I_{d i}-I\right) / I+\left(e_{a i}-e_{d i}\right) /\left(n e_{d i}\right)+D_{i}+C_{c D C l},
$$

where $I_{d i}=\left(I_{+d i}-I_{-d i}\right) / 2$ aave. dc current

$e_{d i}=\left(e_{+d i}+e_{-d i}\right) / 2$ ave. TCC emf with $\pm \mathrm{DCI}$ applied $\}$

$n=$ the TCC power coefficient at the nominal voltage

$D_{i}=$ the ac-dc difference of the TCC at the nominal voltage at $f_{i}$

$C_{C D C I}=$ the average calibrator DCI correction. 
The DMM correction at each frequency $C_{d A C I i}$ is given by:

$$
C_{d A C I i}=\left(I\left(1+C_{c A C l i}\right)-R_{a i}\right) / I \text {. }
$$

As the frequency increases the calibrator becomes more sensitive to the load imposed by the TCC and the test DMM. Therefore, for the highest accuracy test of a particular DMM type, the above procedure must be performed using that DMM type. The second set of DMM readings $R_{b i}$ is used to generate unique corrections $C_{C A C i(X)}$ for all DMMs of that type (type-X DMMs for this example). These corrections apply only when a type-X DMM is connected to the calibrator using the same connectors and cables that were used to obtain the set of $R_{b i}$ readings. These corrections are given by:

$$
C_{c A C I i(X)}=C_{c A C I i}+C_{d i(X)} \text {, }
$$

where $C_{d i(X)}=\left(R_{b i(X)}-R_{a i(X)}\right) / I$ represents the additional correction needed to compensate for the difference between the calibrator output current (programmed to $I_{i}$ ) with the TCC and type-X DMM connected, and with only the type-X DMM connected.

As with DCI, ACI measurements are made at various compliance voltages and a correction factor for the calibrator compliance voltage is applied when testing a DMM type that has not been characterized with the system calibrator.

Control charts for the ACI function corrections of the system calibrator and DMMs are also quite complex covering current, frequency, and DMM type (or compliance voltage). A sample chart for the ACI calibrator corrections at $1 \mathrm{~A}$, at $1 \mathrm{kHz}$ for one of the DMM types is shown in Fig. 11. ACI corrections are less predictable than the DCI corrections; however, until the drift patterns are better

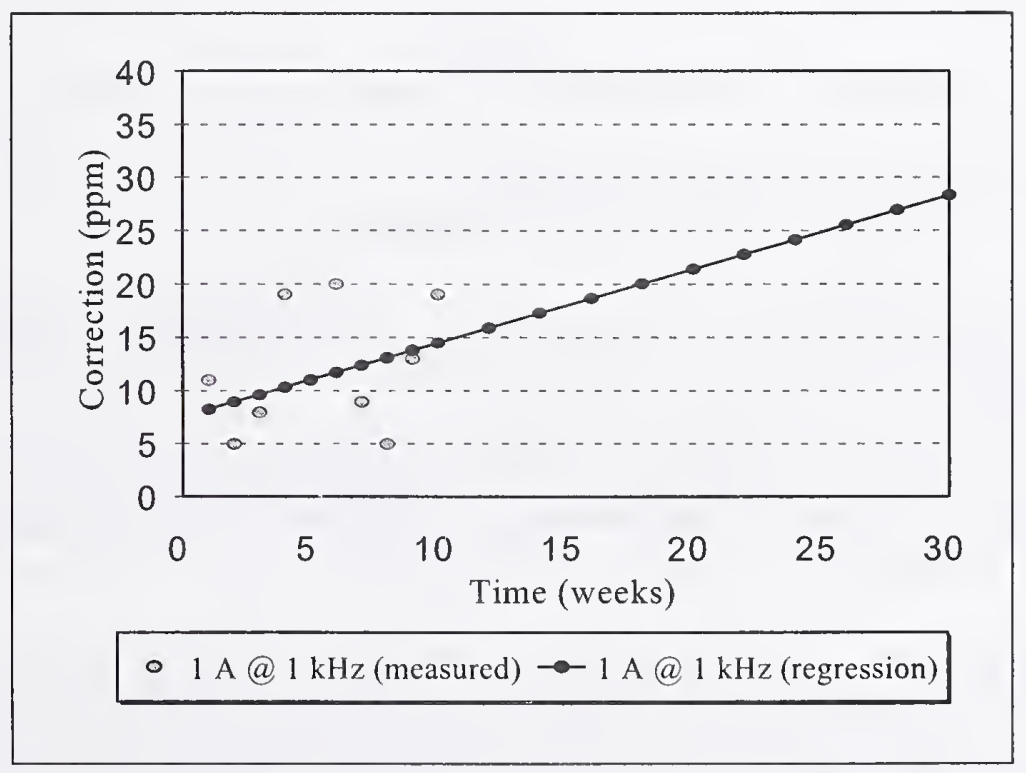

Fig. 11. Control chart with measured and predicted corrections for the MCS calibrator for ACI. 
understood, a least squares linear fit to the correction time series is performed and a linear equation is used to predict the calibrator correction between calibrations. The system software also linearly interpolates between calibration points to compute corrections over the full range. Specific software corrections for the DMM type being tested are applied where possible and all interconnection parameters are specified. In a similar manner, when a calibrator is tested using a system DMM, the DMM type and all interconnection parameters are specified.

\subsubsection{Currents from $2 \mathrm{~mA}$ to $10 \mathrm{~A}$ from $0.01 \mathrm{~Hz}$ to $1 \mathrm{kHz}$}

The NIST DSS and Transconductance Amplifier are employed to perform high accuracy, low frequency current tests of DMMs. A DMM (on its DCI function) is used to measure the dc current of each of the steps in the waveform approximation. The rms value of the output current $I_{s}$ is computed by this step calibration:

$$
I_{s}=\left(\sum i_{i}^{2} / N\right)^{1 / 2}
$$

where $i_{i}=$ the dc currents of the steps

$N=$ the number of steps per period.

The frequency response error of the synthesized signal is measured between $20 \mathrm{~Hz}$ and $1 \mathrm{kHz}$ using a calibrated TCC. Below $20 \mathrm{~Hz}$, it is assumed that the rms value remains constant to within $\pm 2 \mu \mathrm{A} / \mathrm{A}$. At currents between $100 \mathrm{~mA}$ and $10 \mathrm{~A}$, the frequency response out to $1 \mathrm{kHz}$ is flat to within $\pm 100 \mu \mathrm{A} / \mathrm{A}$. This performance degrades at lower currents; however, even at $1 \mathrm{~mA}$, the DSS may be treated as an ac calibrator with zero correction below $20 \mathrm{~Hz}$. DMMs calibrated using the DSS are assigned corrections $C_{d D C I i}$ by:

$$
C_{d D C I i}=\left(I_{s}\left(1+C_{D S S i}\right)-R_{b i}\right) / R_{b i}
$$

where $R_{b i}=$ the DMM reading at frequency $f_{i}$

$C_{D S S i}=$ the DSS correction to $I_{s}$ at frequency $f_{i}$.

Again, a least squares linear fit to the correction time series is performed and a linear equation is used to predict the calibrator correction between calibrations. The system software also linearly interpolates between calibration points to compute corrections over the full range. Specific software corrections for the DMM type being tested are applied where possible and all interconnection parameters are specified. In a similar manner, when a calibrator is tested using a system DMM, the DMM type and all interconnection parameters are specified.

Measurements are performed at a specific set of currents and frequencies from $1 \mathrm{~mA}$ to $1 \mathrm{~A}$ and $0.1 \mathrm{~Hz}$ to $1 \mathrm{kHz}$. Measurements can be made at other than the calibrated points; however, because the corrections at these points are interpolated estimates, the MCS uncertainties are somewhat larger. The Type B standard uncertainties of the MCS ACV function are given in Table 8. 
Table 8

MCS Type B Standard Uncertainties for ACI

\begin{tabular}{||c|c|c|}
\hline Current Range & Calibrated Points & Full Range \\
\hline $1 \mathrm{~mA}$ to $10 \mathrm{~A}$ & $(50+2 \mathrm{f}) \mu \mathrm{A} / \mathrm{A}$ & $(150+3 \mathrm{f}) \mu \mathrm{A} / \mathrm{A}$ \\
\hline
\end{tabular}

Where $\mathrm{f}=$ test frequency in kilohertz.

\section{CALIBRATIONS AND TESTS USING THE MCS}

Once the system calibrator and DMMs have been characterized, the MCS is used to test customer's DMMs, calibrators, and related instruments.

Prior to testing, the test instrument is energized in the MCS lab overnight, to allow it to stabilize and to satisfy any warmup requirements. Then, self-calibration or auto-zeroing routines are performed to bring the instrument to its rated uncertainty.

\subsection{Calibration of DMMs Using the MCS Calibrator}

Unless otherwise requested, the DMM is calibrated at its input terminals. Using an adjustable platform, the DMM terminals are brought "nose-to-nose" with the MCS calibrator terminals so that only a few centimeters of connectors are required to interconnect them as shown in Fig. 12. The calibrators have six output terminals including outputs (hi and lo), sense (hi and lo), guard and ground. Test DMMs have a similar set of input terminals. Tables $9-11$ list the interconnections made for typical DMM calibrations.

Table 9

Connections and configuration for a $\mathrm{DCV}$ or $\mathrm{ACV}$ calibration

\begin{tabular}{|c|c|}
\hline From & To \\
\hline Calibrator voltage output hi & DMM input hi \\
\hline Calibrator voltage output lo & $\begin{array}{c}\text { DMM input lo } \\
\text { Calibrator guard and ground }\end{array}$ \\
\hline
\end{tabular}

The calibrator is programmed to local sense and local guard, and the DMM is programmed or switched to local guard. 
Table 10

Connections and configuration for a DCI or ACI calibration

\begin{tabular}{|c|c|}
\hline From & To \\
\hline Calibrator current output hi & DMM current input hi \\
\hline Calibrator current output lo & $\begin{array}{c}\text { DMM current input lo } \\
\text { Calibrator guard and ground }\end{array}$ \\
\hline
\end{tabular}

The calibrator is programmed to local guard, and the DMM is programmed or switched to local guard.

Table 11

Connections for a DCR (4-wire) calibration

\begin{tabular}{|c|c|}
\hline From & To \\
\hline Calibrator resistance output hi & DMM resistance input hi \\
\hline Calibrator resistance output lo & DMM resistance input lo \\
\hline Calibrator resistance sense hi & DMM resistance sense hi \\
\hline Calibrator resistance sense hi & DMM resistance sense hi \\
\hline Calibrator guard & $\begin{array}{c}\text { DMM guard } \\
\text { Calibrator ground }\end{array}$ \\
\hline
\end{tabular}

The calibrator is programmed to remote sense and local guard, and the DMM is programmed or switched to local guard.

Calibrations are performed by programming the MCS calibrator to the desired function and setting, triggering the DMM (the first reading is ignored), and recording the next $\mathrm{N}$ readings.

The average reading of the DMM under test $R$, its associated correction $C_{T D M M}$, the system calibrator setting $S$, and its correction $C_{S C A L}$ are related by the following equation:

$$
R\left(1+C_{T D M M}\right)=S\left(1+C_{S C A L}\right)
$$


Certain DMMs have software correction tables that are used to keep the instrument within a particular specification. Correction tables are updated by applying a reference signal from the MCS calibrator and then initiating a GPIB "correction" command that changes the appropriate correction value until the DMM displays the proper value to within a selectable tolerance. Both the MCS software and the Wavetek 4950 software have this capability. Repeat tests are performed to verify that the DMM correction table has been accurately modified. This service represents a change in the long-standing NIST policy of not adjusting instruments submitted for test. However, instead of making an analog adjustment which can not generally be undone, in this case the adjustment is digital. The initial corrections are stored in the instrument and the residual corrections are given in the test report. The uncertainties of the residual corrections are based on the standard uncertainty of the calibrator and the standard deviation of the repeat tests.

\subsection{Calibration of Calibrators using the MCS DMM}

Unless otherwise requested, calibrators are tested at their output terminals using the setup shown in Fig.12. The interconnections are the same as those given in Tables $9-11$. The test calibrator setting $S$ is related to the system DMM reading $R$ :

$$
S\left(1+C_{T C A D}\right)=R\left(1+C_{S D M M}\right),
$$

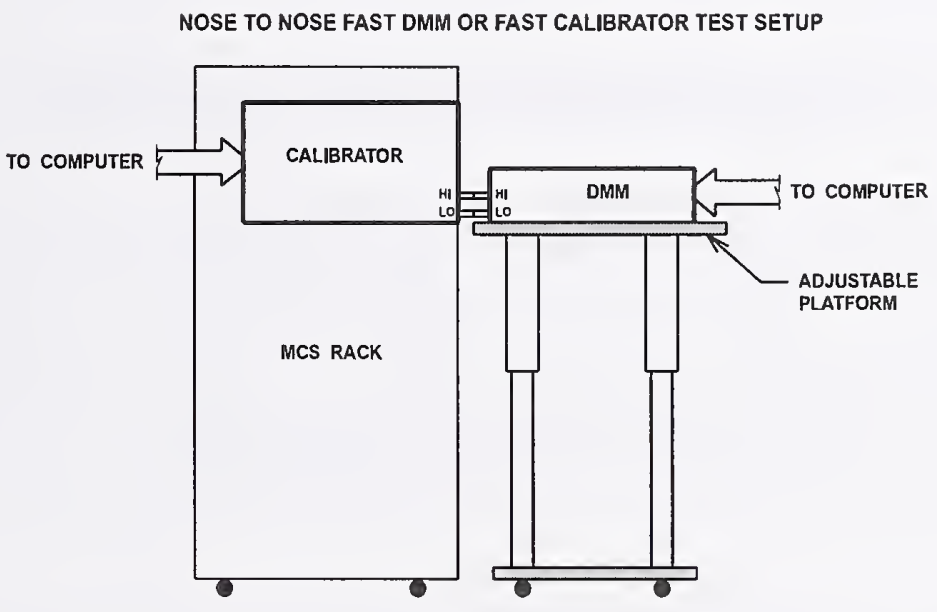

Fig. 12. Setup to calibrate a test DMM using the characterized MCS calibrator.

where $C_{T C A L}$ is the test calibrator correction and $C_{S D M M}$ is the system DMM correction.

As with DMMs, certain calibrators have software correction tables that are used to keep the instrument within a particular specification. Correction tables are updated by applying a nominal signal from the test calibrator to the MCS DMM, and then initiating a GPIB "correction" command, 
which changes the appropriate correction value until the DMM displays the proper value to within a selectable tolerance.

\subsection{High Accuracy Special Test of DMMs and Calibrators}

The highest accuracy test of a DMM or calibrator involves direct comparisons against the standards that are used to characterize the MCS DMMs and calibrator using the techniques described in 3.4. These are inherently more time consuming and expensive than the automated tests described in 4.2 .

\subsection{Special Test of Low Voltage Thermal Voltage Converters}

Low voltage thermal voltage converters are tested using the MCS multirange thermal voltage converter. Tests are performed by placing the two instruments nose-to-nose, and then applying ac and dc voltages, while monitoring the output of each device. The ac-dc difference corrections for the TVC under test are calculated by using the techniques described in 3.4.

\subsection{Special Test of Micropotentiometers}

Micropotentiometers are tested using the MCS multirange thermal voltage converter. Tests are performed by connecting the $\mu$ pot input to the calibrator output and the $\mu$ pot output to the thermal converter input and then applying ac and dc voltages, while monitoring the output of each device. The ac-dc difference corrections for the $\mu$ pot under test are calculated using the techniques described in 3.4 .

\section{QUALITY CONTROL AND UNCERTAINTIES}

The MCS relies on standards that are calibrated in other laboratories in the NIST Electricity Division and it is important to maintain traceability back to these standards. Each of the support artifacts or instrument standards is calibrated on a regular interval (normally once a year) and a control chart describing its value and uncertainty at any time is maintained. The MCS calibrator and DMMs are normally characterized four times a year using the support standards. The calibrator and DMMs are also intercompared several times per month to track long-term stability. The standard deviation of this intercomparison represents a composite stability figure for the calibrator and two DMM types.

The standard uncertainty of each function in the MCS calibrators and DMMs is based on the standard uncertainties of the associated support instrument, the repeatability of the transfer process, and the long-term stability of the calibrator. The figures given in the tables in section 3 represent onestandard deviation (1-sigma) estimates of the system standard uncertainty. Note: These are composite figures that serve for both the calibrator and the DMMs. Over a large parameter space the figures apply equally to both; however, at high frequencies, the stability of the calibrator may be significantly better than the DMMs. Under these conditions, a different set of uncertainty figures is used. The total uncertainty of a test performed using the MCS includes the short-term stability of the instrument under test. For example, the uncertainty of a test DMM calibrated by the MCS calibrator on the ACV function depends on the uncertainties of the following parameters: 
1. The ac-dc difference of the multirange TVC, $U_{T V C}$ (see 3.4)

2. The correction of the dc voltage function of the calibrator, $U_{D C}$ (see 3.1).

3. The standard deviation of the process in which the calibrator ac voltage is compared to its dc voltage, $U_{S D}$ (see 3.4).

4. The long-term stability of the calibrator/DMM at the test point, $U_{L T S}$ (the standard deviation of periodic comparisons with a system DMM).

5. The short-term stability of the test, $U_{S T S}$ (the standard deviation of the measurement including the MCS calibrator and the instrument under test).

These values (all 1-sigma estimates) are combined according to the procedures recommended in [6] to give the expanded total uncertainty, $U_{T}$

$$
U_{T}=2\left(U_{S D}{ }^{2}+U_{L T S}{ }^{2}+U_{S T S}^{2}+U_{D C}{ }^{2}+U_{T V C}{ }^{2}\right)^{1 / 2}
$$

where the first three terms are considered to be type A standard uncertainties and the last two are type B standard uncertainties.

\section{ACKNOWLEDGMENTS}

The authors wish to acknowledge those people who helped in the development of the MCS: Barry Bell, the group leader of the Electronic Instrumentation and Metrology Group, for his strong support; Ron Dzuiba, and Dean Jarrett for sharing their expertise in resistance measurements; Dick Steiner and June Sims for assisting in de voltage support; Joe Kinard and Tom Lipe for providing ac-dc transfer calibrations and overall guidance in ac-dc voltage measurement techniques; Robert Palm for prototyping and drafting support; and Kathy Magruder for running tests, and performing much of the data reduction necessary for the MCS. 


\section{REFERENCES}

[1] N. M. Oldham, M. E. Parker, A. M. Young, and A. G. Smith, "A High-Accuracy 10 Hz $1 \mathrm{MHz}$ Automatic AC Voltage Calibration System," IEEE Trans. Instrum. Meas., IM-36, pp.883-887, Dec. 1987.

[2] N. M. Oldham, "New Low-Voltage Standards in the DC to 1-MHz Frequency Range," IEEE Trans. Instrum. Meas., Vol. 40, No. 2, pp. 368-372, Apr. 1991.

[3] N. M. Oldham, P. S. Hetrick, "A Calculable, Transportable Audio-Frequency AC Reference Standard,” IEEE Trans. Instrum. Meas., Vol. 38, No. 2, Apr. 1989.

[4] N. M. Oldham, “A 50-ppm AC Reference Standard which Spans $1 \mathrm{~Hz}$ to $50 \mathrm{kHz}$," IEEE Trans. Instrum. Meas., IM-32, No. 1, Mar. 1983.

[5] C.A. Hamilton et al., "The NBS Josephson Array Voltage Standard," IEEE Trans. Instrum. Meas., IM-36, No. 2, pp 258-261, June 1987.

[6] B. N. Taylor, C. E. Kuyatt, "Guidelines for Evaluating and Expressing the Uncertainty of NIST Measurement Results," NIST Technical Note 1297, 1994 Ed.

[7] R.F. Dziuba et al, "NIST Measurement Service for DC Standard Resistors," NIST Technical Note 1298, 1992.

[8] N.M. Oldham, P.S. Hetrick, and X.Zeng, "A Calculable, Transportable Audio-Frequency AC Reference Standard," IEEE Trans. Instrum. Meas., Vol. 38, No. 2, pp. 368-371, April 1989.

[9] J.R. Kinard et al, "NIST Measurement Services: AC-DC Difference Calibrations," NIST Special Publication 250-27, May 1989. 


\section{THE SP 250 SERIES ON NIST MEASUREMENT SERVICES*}

SP 250-1 Spectral Radiance Calibrations

PB87179883

SP 250-2 Far Ultraviolet Detector Standards PB87227609

SP 250-3 Radiometric Standards in the Vacuum Ultraviolet PB87227625

SP 250-4 Fricke Dosimetry in High-Energy Electron Beams PB88110374

SP 250-5 Alpha-Particle Calibrations PB88168620

SP 250-6 Regular Spectral Transmittance PB88108550

SP 250-7 Radiance Temperature Calibrations PB88123674

SP 250-8 Spectral Reflectance PB88109905

SP 250-9 Calibration of Beta-Particle-Emitting Ophthalmic Applicators PB88108535

SP 250-10 Radioactivity Calibrations with the " $4 \pi$ " Gamma Ionization Chamber and Other Radioactivity Calibration Capabilities PB88123708

SP 250-11 Dosimetry for High Dose Applications PB88201587

SP 250-12 Neutron Personnel Dosimetry PB87227617

SP 250-13 Activation Foil Irradiation with Californium Fission Sources PB88217443

SP 250-14 Activation Foil Irradiation by Reactor Cavity Fission Sources PB88217435

SP 250-15 Photometric Calibrations PB88153747

SP 250-16 Calibration of X-Ray and Gamma-Ray Measuring Instruments PB88211826

SP 250-17 The NBS Photodetector Spectral Response Calibration Transfer Program PB88201595

SP 250-18 Neutron Source Strength Calibrations PB88211818

SP 250-19 Calibration of Gamma-Ray-Emitting Brachytherapy Sources PB89193858

SP 250-20 Spectral Irradiance Calibrations PB88123781
SP 250-21 Calibration of Beta-Particle

Radiation Instrumentation PB88201579

SP 250-22 Platinum Resistance Thermometer Calibrations PB88138367

SP 250-23 Liquid-in-Glass Thermometer Calibration Service PB89128888

SP 250-24 Standard Cell Calibrations PB88123690

SP 250-25 Calibration Service for Inductive Voltage Dividers

SP 250-26 NBS Phase Angle Calibration Services PB88225636

SP 250-27 AC-DC Difference Calibrations PB892222616

SP 250-28 Solid-State DC Voltage Standard Calibrations PB88168703

SP 250-29 Traceable Frequency Calibrations PB88168364

SP 250-30 GOES Satellite Time Code Dissemination: Description and Operation PB88168760

SP 250-31 Mass Calibrations PB89153894

SP 250-32 A Calibration Service for $30 \mathrm{MHz}$ Attenuation and Phase Shift PB88238324

SP 250-33 A Calibration Service for Voltage Transformers and High-Voltage Capacitors PB882252903

SP 250-34 High Vacuum Standard and Its Use PB89193841

SP 250-35 The Calibration of Thermocouples and Thermocouple Materials PB89209340

SP 250-36 A Calibration Service for Current Transformers PB91216770

SP 250-37 Photometric Calibrations

SP 250-38 NIST Leak Calibration Service PB92149772

SP 250-39 NIST Pressure Calibration Service

SP 250-40 Absorbed-Dose Calibration of lonization Chambers in a ${ }^{60}$ Co Gamma-Ray Beam SN003-003-03034-1 \$2.00

* Entries containing a stock number (SN003-003-) and price can be purchased from the Superintendent of Documents, U.S. Government Printing Office, Washington, DC 20402. GPO will accept checks, money orders, VISA, and MasterCard. For more infomation, or to place an order, call (202) 512-1800. Be sure to cite the stock number on all orders.

Entries containing PB numbers can be purchased from the National Technical Information Service, Springfield, VA 22161. NTIS will accept American Express in addition to the payment methods listed for GPO. For more information call (703)487-4650; to place an order call (800) 553-6487. Fax: (703) 321-8547. Be sure to cite the PB number on all orders.

Entries without stock or PB numbers are in preparation. 


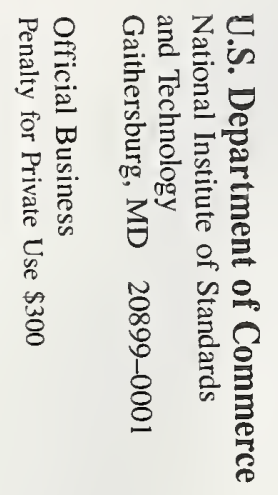

